\title{
DO DISCURSO ENQUANTO CONSTITUINTE DA REALIDADE
}

\author{
Loraci Hofmann Tonus
}

Prof ${ }^{a}$ do CEFET-PR, unidade de Pato Branco. Mestre em

Educa;ao pela UNESP.

\begin{abstract}
RESUMO: O artigo consiste em um estudo sobre o discurso produzido por determinadas classes sociais e disseminado pelos veículos de comunicação com o objetivo de contribuir para a constituição da realidade social. O objetivo da autora é observar os mecanismos de funcionamento do discurso e a forma como as idéias veiculadas pela mídia passam a fazer parte da consciência individual e coletiva e interferem na construção do cotidiano ao determinarem padrões de comportamento, modos de pensar, agir e sentir. Reitera-se que, através da linguagem, e por ela, os mundos se constituem ou deixam de existir.
\end{abstract}

PALAVRAS-CHAVE: Discurso - Realidade social - Mídia

ABSTRACT: The article consist in a study about a the speech made by determined social classes and disseminated by communication means with the aim of contributing to the constitution of the social reality. The author's objective is to observe the mecanisms of the speech working and the form how the transmitted ideas by the midia constitute part of the individual and collective conscience and interfere on the daily construction when determine behavior standards ways of thinking, acting and feeling. The text reiterates that, through the language, and by it, the worlds are constituted or don't exist.

KEY WORDS: Speech - Social reality - Midia

\section{Introdução}

...o discurso [...] é também, e sobretudo, um produtor da cena (DIAS, 1995: 70).

Muito já se refletiu sobre a linguagem com o objetivo de se compreender suas características e multiplicidade de funções. O filósofo Wittgenstein, por exemplo, afirmou que

a linguagem engendra superstições das quais é preciso desfazer-se, e a filosofia deve ter como tarefa primordial o esclarecimento que permita neutralizar os efeitos enfeitiçadores da linguagem sobre o pensamento. [...] É necessário não querer descobrir o oculto sob a linguagem, mas abrir os olhos para ver e desvendar como ela funciona (1989, p.15).

É possível considerar, da fala wittgensteiniana, um certo temor da linguagem que engendra superstições e enfeitiça o pensamento. Isso porque engendrar e enfeitiçar são termos cujo teor semântico conduz à idéia de envolvimento e manipulação. Pelo uso da linguagem, seria possível dominar outros seres humanos, levando-os a abraçarem causas, crenças, atitudes. Para não ser enredado pela linguagem seria necessário descobrir, através da reflexão, quais os artifícios de que ela dispõe para conseguir tamanho poder de convencimento. Vê-se que o olhar de Wittgenstein dirigiu-se à estrutura da organização lingüística propriamente dita, ao seu funcionamento.

A pesquisadora Encarnación Sobriño (1986, p.68), por sua vez, propõe uma abordagem para o estudo da linguagem a partir de um ponto de vista sociológico capaz de abarcar, além da língua enquanto sistema particular de signos, o sistema de idéias que se 
exprime através da língua. Ou seja, propõe, também, a análise semântica dos discursos, em especial daqueles que aparentemente parecem focalizar aspectos parciais ou aparecer como não compromissados ou mais ou menos 'neutros' ideologicamente. Sugere abarcar, em síntese, também o aspecto desprezado por Wittgenstein: o subentendido, o pressuposto, a mensagem ideológica subjacente à aparente neutralidade. Orlandi (1994, p.299) corrobora essa visão de Sobriño ao afirmar que a língua não é apenas código e não é um instrumento de comunicação ideologicamente neutro.

Sobriño emprega o termo discurso para nomear os textos escritos que constituirão o corpus de seu trabalho de pesquisa. Mas discurso não é somente o texto escrito. Pode ser também a língua se materializando no texto produzido por um sujeito individual ou coletivo que escreve ou fala, ou então, como querem os pesquisadores que se aliam à teoria da Análise do Discurso (Pêcheux, 1995), o conjunto de textos reais ou imaginários que se poderia produzir no interior de uma dada formação discursiva[1]. A partir dessa última conceituação, que adotaremos neste trabalho, podemos observar na atual conjuntura histórica o predomínio de discursos como o neoliberal, o tecnológico, o da globalização, o da sociedade de conhecimento, entre outros.

Nossa intenção neste artigo é examinar, como queria Wittgenstein, os mecanismos de funcionamento utilizados no discurso e, ainda, de acordo com a proposta de Sobriño, fazer a leitura de algumas idéias veiculadas pelo corpus que definimos: os discursos efetuados pelos meios de comunicação da imprensa falada e escrita no atual momento histórico de início de um novo milênio.

Pretendemos examinar tais discursos como projetos de intervenção no real, [...] sua interferência na cena histórica mundial (Dias, 1995, p.67). Partiremos de uma premissa básica: há discursos capazes de produzir a realidade social na medida em que determinam, para o conjunto da sociedade ou para determinadas classes, modos de pensar e agir que constituirão o seu cotidiano e, portanto, a sua história.

\title{
1. Do discurso e da performance
}

\begin{abstract}
Os mundos humanos são construídos por meio de linguagem, preservados por ela, ensinados e transmitidos [...] pela conversação. Um mundo que deixa de ser falado deixa de existir (Alves, 1982, p.22).
\end{abstract}

Para Wittgenstein (1989, p.11), uma língua é ensinada a uma criança através do ensino ostensivo das palavras, estabelecendo-se relações associativas entre palavras e coisas. Esse ensino ostensivo se dá através da intensa repetição, até o momento em que a simples menção da palavra desencadeie a imagem mental da coisa representada.

Ao longo da trajetória humana, a consagração dos determinados modos de pensar o mundo deu-se invariavelmente da mesma forma: pela repetição do discurso. Um discurso 
repetido por diferentes sujeitos individuais dotados de certa influência tem a capacidade de interferir no modo de pensar e agir do sujeito coletivo. Como cada época apresenta um conjunto de palavras-chave capazes de exprimir a ideologia hegemônica, é preciso, para que a hegemonia se estabeleça, repeti-las até que sejam absorvidas e passem a fazer parte do senso comum. Esse ensino ostensivo das palavras - ou elucidação ostensiva - tem por objetivo promover a repetição delas na fala dos indivíduos, bem como a absorção de seu significado. Ou não. Apenas a repetição, mesmo sem ter-se a clareza de seu significado. $O$ que importa é que o conjunto de idéias que o discurso repetido carrega em si passe a fazer parte do modo de se pensar e representar o mundo e, a partir daí, desencadeie ações que contribuam para perpetuar esse discurso.

É interessante observar o poder de alguns discursos, capazes de atravessar os séculos praticamente intocados. É o caso, por exemplo, daquele que preconiza o preconceito sexista a respeito da capacidade intelectual e moral das mulheres. Consideradas inferiores e acusadas de conduzirem a humanidade ao pecado por homens com forte poder de argumentação, como Santo Agostinho, por exemplo, as mulheres sofreram o assujeitamento ao universo dominantemente masculino. É inegável que o mundo ocidental conseguiu, nos últimos anos, superar em parte esse discurso. Mas é inegável também que a força argumentativa e a repetição dessa ideologia foram tão bem realizadas que até hoje há quem acredite em suas teses e as empregue na vivência diária.

O assujeitamento do indivíduo a formas de pensar se dá principalmente no nível inconsciente. $O$ discurso religioso, com seus dogmas e sua catequese são representativos disso. Alves (1982, p.25-26) afirma que

a linguagem religiosa [...] organiza a experiência, mapeia os caminhos, indica as zonas obrigatórias, as permitidas, as proibidas, diz o que deve ser feito e o que não pode ser feito. Cada religião é uma organização arquitetônica do real. [...] E será este corpo lingüístico que irá dizer ao crente o que deve sentir,[...] o que deverá fazer.

Uma criança que tenha ouvido repetidamente que deve 'guardar domingos e festas de guarda', isto é, louvar a Deus nesses dias freqüentando a igreja para participar de cerimônias religiosas, pode, quando adulta, racionalizar sobre o imperativo de tal discurso, considerá-lo arbitrário e deixar de participar das funções da igreja. Mas cada vez que se defrontar com pessoas saindo de um templo sentirá aflorar de dentro de si um irreprimível sentimento de culpa, de 'dever não cumprido'. São os ecos do discurso antigo que continuam a realizar seu trabalho de submissão do sujeito a modelos de interpretação do mundo. Dependendo da força com que esse discurso se tenha plasmado no inconsciente do sujeito, este poderá, eventualmente, voltar a participar do culto de alguns domingos como forma de redimir-se diante de si próprio e de Deus. Haveria aí, então, uma prova cabal de que o discurso intervém na concretização da realidade.

Assim, nas ações praticadas pelo sujeito ideologicamente condicionado, ocorre aquilo que Orlandi chamou de ilusão da autonomia. Nesse sentido, 
realidade mas assegurar a permanência de uma certa representação' (Vignaux, 1979). Por isso há, na gênese de todo discurso, o projeto totalizante de um sujeito, projeto este que o converte em autor (Orlandi, 1996, p.55).

O sujeito se constitui em autor quando produz seu próprio texto (Orlandi, 1996), quando fala ou escreve repetindo ou interpretando (até onde é possível a interpretação) o que leu, viu ou ouviu. É enquanto autor que mostra ter incorporado outros discursos e, sem se dar conta, torna-se ele também um reprodutor e difusor de idéias, um manipulador. É essa a perversidade maior de alguns discursos: impedir que o sujeito se dê conta do processo de assujeitamento ideológico que sofre. Aqui talvez fosse conveniente que nos perguntássemos a respeito de como a 'nossa' realidade está se constituindo, quais os discursos que estão sendo repetidos pelas mídias para construírem formas de pensar e agir para o povo brasileiro.

\section{Da polissemia possível à paráfrase imposta}

O direito de falar é uma forma de poder e o direito privilegiado e exclusivo de monopólio na formulação do discurso implica exercer influência eficaz, embora invisível e silenciosa, sobre os indivíduos (Foucault, 1970, In Costa, 1995, p.91).

Orlandi (1996), em seus estudos sobre os discursos, divide-os em três tipos específicos. Entre diversos critérios que usa para diferenciá-los, está aquele que consideramos relevante para este trabalho: o grau de polissemia ou de paráfrase que contêm. Embora não existam tipos puros, apenas discursos que tendem para, é possível classificá-los em discurso lúdico; discurso autoritário e discurso polêmico, conforme passaremos a especificar.

\subsection{Discurso lúdico:}

É caracterizado pela interpretação individual, pela absoluta liberdade de pensamento. É o discurso da ruptura geral com os parâmetros interpretativos vigentes de se pensar o mundo. Tende para a total polissemia (Orlandi, 1996, p.24). Esse tipo é encontrado transitando nos veículos de comunicação como objeto de curiosidade, exemplo de identificação do non sense alheio e serve, não raro, para desviar a atenção do público de questões econômicas e político-sociais que o afligem. Sua apresentação na televisão vem acompanhada de um franzir de sobrancelhas, de um sorriso ou comentário irônicos. Quando apresentado em um texto escrito, normalmente é bastante questionado.

Porém, apesar de ser pouco prestigiado, esse tipo de discurso acaba, às vezes, estabelecendo novos padrões estéticos ou comportamentais. Foi o caso do cubismo, na pintura, dos movimentos da vanguarda européia do início do século, como o futurismo e 0 
dadaísmo, do movimento hippie, nos anos 60 , dentre outros. Hoje talvez pudéssemos apontar como exemplos de discurso lúdico aqueles que aprovam a clonagem de órgãos humanos no corpo de animais, ou ainda os que defendem o congelamento de corpos vivos para um pretenso descongelamento em um futuro distante.

\subsection{Discurso autoritário:}

O tipo 'autoritário' é o que tende para a paráfrase (o mesmo) [...], em que a polissemia é contida (procura-se impor um só sentido) (Orlandi, 1996, p.24). Esse discurso não abre possibilidades para que o interlocutor interprete a seu modo a realidade, pois o sentido único já está nele constituído. Um exemplo desse tipo de discurso seria aquilo que Georg Klaus chama de univocidade semântica do mundo capitalista, engendrada por intelectuais responsáveis pela constituição do cenário que mantém o povo encantado (In Pêcheux, 1995, p.283).

Desnecessário acrescentar que, em nossa forma de sociedade atual, o discurso autoritário é dominante. [...] E isso significa que ao dizer que [...] é dominante, estamos afirmando que o uso da linguagem está polarizado para o lado da paráfrase (Orlandi, 1996, p.24).

Para que a paráfrase predomine, a sociedade contemporânea sofre uma espécie de patrulha ideológica patrocinada pela mídia que, com raras exceções, esmera-se no intento de construir um pensamento nacional homogêneo. Apenas a uns poucos é dado o direito de interpretar a realidade e, logo, de produzir sentidos para ela. À maioria é dado tão somente o direito de concordar com essa interpretação e incluir-se no rol dos seguidores conformados ou de se auto-excluir sempre que optar pelo pensamento independente[2]. (Retomaremos a auto-exclusão no transcurso da análise sobre o discurso polêmico).

Assim, a interpretação constitui-se em privilégio, um monopólio pertencente aos grupos sociais hegemônicos, cujos aparelhos ideológicos encarregam-se de gerir a memória coletiva. Essa situação caracteriza aquilo que Pêcheux (1997, p.58) identificou como a divisão social do trabalho de leitura[3], em que é dado,

a alguns, o direito de produzir leituras originais, logo 'interpretações', constituindo, ao mesmo tempo, atos políticos (sustentando ou afrontando o poder local); a outros, a tarefa subalterna de preparar e de sustentar, pelos gestos anônimos do tratamento 'literal' dos documentos, as ditas 'interpretações'...

Temos, então, no trabalho de ler a realidade, dois papéis marcantes: o primeiro é o do autor de um discurso dito 'fundador', que interpreta o mundo de acordo com a formação discursiva de sua classe social (ou de acordo com a ideologia da instituição que o financia). Gramsci (In Mochcovitch, 1988, p.18) chamou-o de intelectual orgânico. Quando produtor de um discurso autoritário, seu empenho consiste em argumentar convincentemente para provocar ou evitar mudanças no status quo e isso, segundo Piotte (In Mochcovitch, 1988, p.20), significa assegurar o consentimento passivo, ou mesmo ativo, das classes dominadas 
à direção que imprime à sociedade a classe dominante. Para tanto, esse intelectual usa estatísticas, termos técnicos e científicos e maneja a linguagem da ciência para dar credibilidade à sua leitura. $O$ segundo papel poderia ser imputado, hoje, ao trabalho realizado por profissionais das mais diversas áreas, especialmente da mídia a serviço dos donos do poder político e econômico, e consiste em organizar estratégias para impor ao público a interpretação do primeiro.

Essa divisão social do trabalho de leitura não é novidade na história das sociedades. De acordo com Pêcheux (1997, p.58), na Idade Média

a divisão começou no meio dos clérigos, entre 'alguns' deles, autorizados a ler, falar e escrever em seus nomes (logo, portadores de uma leitura e de uma obra próprias) e o 'conjunto de todos os outros', cujos gestos incansavelmente repetidos (de cópia, transcrição, [...] codificação, etc.) constituem também uma 'leitura', mas uma leitura impondo ao sujeito-leitor seu apagamento atrás da instituição que o emprega. [...] é o apagamento de si na prática silenciosa de uma leitura consagrada ao serviço de uma lgreja, de um Estado, ou de uma empresa.

Talvez o maior dano produzido pelo discurso do tipo autoritário seja justamente estabelecer os monopólios interpretativos empenhados em legitimar apenas os discursos parafrásticos e considerar como 'tortos', porque fora da realidade, quaisquer outros que procurem modificar idéias já estratificadas. Um exemplo claro disso no passado recente da história do Brasil foram os ataques diários promovidos pelos veículos de comunicação com o objetivo de abalar o discurso difundido pelo Movimento dos Sem-Terra. Apoiando-se no uso de imagens descontextualizadas e em exceções, buscou-se descaracterizar o movimento enfatizando aspectos como a violência, a presença, em seus quadros, de gente que já dispunha de um pedaço de terra, a necessidade de se garantir o direito de propriedade, a falta de inteligência dos seus líderes através de críticas severas ao seu discurso. A finalidade dos ataques era jogar a opinião pública contra esse movimento popular e, assim, arrefecer seu ímpeto. Hoje, quando o Ministério da Reforma Agrária contabiliza como feitos importantes o número de famílias assentadas, costuma imputar tudo à ação e à boa vontade do governo, ocultando o fato de que tais ações jamais seriam efetuadas sem a pressão do povo organizado.

Outro campo em que há predomínio do discurso autoritário é, segundo Bourdieu, o mundo da ciência. Aí disputa-se passo a passo o direito à interpretação e também o monopólio da 'autoridade científica' definida [...] como capacidade técnica e poder social; ou, se quisermos, o monopólio da 'competência científica', compreendida enquanto capacidade de falar e agir legitimamente [...] que é socialmente outorgada a um agente determinado (Bourdieu, 1976, In: Ortiz, 1983,p.122).

Essa competência científica traduz-se na monopolização das decisões a respeito daquilo que será pesquisado ou não, do que merece ser publicado ou não, do que é ciência e do que é pseudociência. E induz à submissão aqueles que estão iniciando seus trabalhos 
de investigação científica, obrigando-os a praticarem certos rituais de vassalagem para terem seus trabalhos reconhecidos pela comunidade científica[4] (Bourdieu, 1976, In: Ortiz, 1983).

Souza Santos diz que a guerra contra os monopólios de interpretação está longe de ser ganha. Ele aponta os dilemas enfrentados por uma sociedade sustentada sobre os pilares de um discurso unilateral e defende a importância de os setores esclarecidos iniciarem um processo de desmonte desse discurso monofônico. É importante, porém, que $O$ processo de desmantelamento dos monopólios seja conduzido de modo a criar mil comunidades interpretativas e não redundar em milhões de renúncias à interpretação (Souza Santos, 1996, p.109).

\subsection{Discurso polêmico:}

O discurso polêmico é o que apresenta um equilíbrio tenso entre polissemia e paráfrase [...], em que o objeto do discurso não está obscurecido pelo dizer, mas é direcionado pela disputa [...] entre os interlocutores, havendo assim a possibilidade de mais de um sentido: a polissemia é controlada (Orlandi, 1996, p.24).

Neste início de milênio, é preciso questionar até que ponto a polissemia é possível e onde o espírito lúcido encontra espaço para manifestar suas opiniões. Por mais que se vanglorie de sua condição de sistema econômico único, o capitalismo vigente parece necessitar da aprovação unânime da sociedade. Mais que isso, está a exigir unanimidade. É provável que aí esteja o sinal mais evidente de sua fraqueza, que a abertura da possibilidade de leituras críticas da realidade poderiam expor inexoravelmente. Daí o clima de patrulhamento ideológico que toma conta de todos os setores sociais, comandado pela mídia televisiva.

A mídia, aliás, parece ter conseguido atingir seu intento de lançar ao ostracismo toda e qualquer oposição ao sistema. As vozes oposicionistas são tachadas de 'inimigas da nação, do progresso, partidárias do quanto pior melhor'. Alves (1982, p.14) já há muito alertava que é necessário pagar um alto preço para contrapor a voz da consciência individual à voz das autoridades constituídas. Acrescentaríamos: à realidade constituída. $O$ universo de discursos no qual transitamos produziu uma espécie de contrato social que impede que os conflitos possam se desenvolver. É importante considerar aqui a perda do poder superador da dialética na medida em que se tenta fingir que a sociedade é homogênea e que nela não há conflitos sociais: a democracia, então, deixa de ser genuína e torna-se algo forçado, onde todos devem pensar e agir em conformidade com o pensamento e ação da maioria, coisa que, em grande parte do tempo, traduz-se na palavra 'passividade'. O sujeito lúcido, crítico e não passivo torna-se persona non grata, acusado de tentar perturbar a ordem estabelecida.

Hoje, um texto que questione a globalização, por exemplo, é visto como um contra senso, já que no bojo do discurso oficial sobre esse fenômeno consta que não há outros caminhos para a economia mundial e para as relações internacionais. No entanto, até mesmo pensadores norte-americanos, como Galbright e Chomski, não hesitam em dizer que 
a palavra globalização teria sido inventada para justificar o imperialismo, a intromissão dos países ricos nas economias dos países da periferia e semiperiferia da riqueza mundial. Se é assim, por que não reagimos, enquanto cidadãos, a esse discurso? Batista Jr (1998, p.73) diz que o fascínio com a 'globalização' é revelador do estado de prostração mental e desarmamento intelectual em que se encontram países como o Brasil. O que se percebe é que a reação é mínima porque a maioria já sofreu a catequese contumaz e já se 'sente' globalizada, mesmo que seu único contato com outros países se dê via TV ou pela contemplação, em prateleiras de supermercados, de produtos estrangeiros que não pode comprar.

Vemos, então, que estratégias diversas são postas em prática com a clara intenção de promover a exclusão do sujeito que se permite uma leitura crítica das relações de poder, o que, em parte, impede que se produza o discurso polêmico.

Foucault sustenta que em qualquer momento da história de uma sociedade, existem códigos culturais que governam o discurso sobre ela, convertendo-se em 'regimes de verdade' que conformam e definem o que deve ser dito e o que deve ser calado, qual o discurso tomado como verdadeiro e quais os mecanismos distintivos entre verdade e erro (Costa, 1995, p.94).

De qualquer forma, e apesar de existirem barreiras preparadas para se impedir sua constituição, o discurso polêmico encontra espaço especialmente dentro das universidades e, a partir daí, abre possibilidades para o confronto de idéias em alguns veículos de comunicação, como os jornais, por exemplo. É curioso, no entanto, observar a postura de neutralidade aparente que esses meios de comunicação procuram transmitir para o leitor desavisado: há sempre uma nota, ao lado do texto polêmico, para esclarecer que ele não representa a opinião dos editores. Quanto à televisão, salvando-se as raras exceções, o debate é censurado ou não permitido. Chegou-se ao auge desse cerceamento durante as eleições presidenciais de 1998, quando sequer se abriu espaço nas redes de televisão para a livre discussão de idéias entre os candidatos.

Mas retomemos o texto de Orlandi com que introduzimos a análise desse tipo de discurso, no trecho em que ela diz que há um equilíbrio tenso entre paráfrase e polissemia na constituição do discurso polêmico. Isso indica o seu caráter a um tempo afirmativo e inovador. Afirmativo porque o sujeito-autor não consegue romper completamente com os modos já consagrados de interpretar a realidade. A inovação está na tentativa de se conduzir o olhar para aspectos encobertos pela interpretação oficial. Esse papel da crítica foi analisado por Souza Santos:

A teoria crítica pós-moderna é afirmativa na medida em que a busca incessante de alternativas se dá pela via da reciclagem das realidades. Prefere correr o risco de ser absorvida e neutralizada a deixar de procurar fragmentos de genuinidade e de oportunidade nos imensos depósitos de manipulação e de dominação que a modernidade foi acumulando (Souza Santos, 1996, p.105). 
Mesmo cientes de que a forma como tem sido possível conduzir-se a polêmica a respeito dos problemas que afligem nossa modernidade está cada vez mais distante da ideal, concordamos com Orlandi (1996, p.25) que tem proposto como um objetivo desejável instalar-se o discurso polêmico, isto é, aquele próprio a uma sociedade crítica. No entanto, cabe aqui também a preocupação de Souza Santos (1996, p.105): como se pode, hoje, afirmar sem ser cúmplice, criticar sem desertar? O exercício da crítica sofreu, ao longo dos últimos anos, uma tão intensa campanha de desvalorização que, conforme Souza Santos (1996, p.89), ao fim dos monopólios de interpretação (da família, da Igreja ou do Estado), levado a cabo com êxito pelo paradigma da modernidade, não parece seguir-se a autonomia de interpretação, mas antes a renúncia à interpretação.

\section{Do domínio interpretativo ao assujeitamento histórico}

As palavras são armas, venenos ou tranqüilizantes (Klaus, In: Pêcheux, 1995, p.281).

Na sociedade contemporânea, 'discurso' é uma palavra cujo sentido específico tem sido pouco questionado. Porém, seu uso pluralizado é um sintoma da grande atenção que o assunto merece. Fala-se em discurso estético, político, filosófico, literário, musical, cinematográfico. Poderíamos ainda nominar as formações discursivas predominantes: a neoliberal, a cientificista, a da sociedade do consumo, a da sociedade do conhecimento, a da sociedade globalizada.

Esse rápido levantamento permite-nos verificar a posição privilegiada que o termo ocupa atualmente. Mas o que queremos reafirmar é que a maneira como o discurso é produzido e, principalmente, a ênfase com que é difundido, torna-o um produtor de realidades, interferindo no modo como a consciência coletiva compreende o mundo. Os grupos hegemônicos que comandam as ações das sociedades globais parecem ter aprendido com Gramsci - justamente com ele, que sonhou em construir uma nova hegemonia mundial, a da classe trabalhadora -, que a repetição é o meio didático mais eficaz para agir sobre a mentalidade popular e que aquele que pretende convencer não deve se cansar jamais de repetir os próprios argumentos (variando literariamente a sua forma) (In Mochcovitch, 1988, p.19). Lição que foi apreendida na essência e seguida na íntegra, ainda que pelo destinatário errado[5].

Marx dizia que o sujeito é determinado historicamente. Orlandi (1994, p.302) reforça essa tese quando fala dos processos de assujeitamento históricos. [...] Em nossa formação social, o assujeitamento se realiza sob a forma da autonomia (interna) e da determinação (externa). Essa determinação externa se daria pelas pressões sociais, familiares, locais, e pela submissão formal do indivíduo ao pensamento social coletivo. Essa submissão, segundo Goldmann (1968), se concretizaria nas ações individuais, que são reflexos da consciência coletiva. 
Se, como afirma Goldmann (1968, p.25), a história é feita pelos esforços dos grupos humanos para encontrarem um conjunto coerente e significativo de respostas para os problemas que Ihes põem as suas relações com o mundo ambiente, a partir do momento em que a sociedade como um todo delega a um grupo específico o poder de interpretar a realidade e de encontrar as respostas convenientes, esse grupo passa a possuir o poder de conduzir a construção da história. De acordo com Costa (1995), quando um grupo assume o monopólio de um discurso, consegue interferir na vida e na liberdade da sociedade como um todo, impondo opções e decisões.

Já faz parte do senso comum que o conhecimento possibilita o acesso ao poder. Porém, em contrapartida, são os detentores do poder quem controlam o acesso ao conhecimento. Quem domina no campo econômico tem poder para decidir o que é interessante que se torne de domínio público. Para tanto, os meios de comunicação postos a seu serviço funcionam como organismos de triagem de informações, uma espécie de filtro através do qual se mantém o controle sobre a massa de leitores, telespectadores ou ouvintes. O conhecimento torna-se um instrumento eficaz para manipular as consciências e conduzir as ações em direção da concretização de uma realidade pré-determinada. Nesse contexto, são sábias as palavras de Henri Lefebvre (In Sobriño, 1986, p.68):

As grandes ideologias produziram a linguagem: entram nas consciências por meio da linguagem. [...] Suas interpretações do mundo operaram e produziram na linguagem (e, portanto, nas consciências) palavras, rodeios. Daí a sua extraordinária eficácia. As ideologias não penetram de fora nas consciências. Jamais desdenharam, para impor-se, a compulsão e a violência, mas se insinuam, persuadem. Os homens aderiram e continuam aderindo às ideologias. Matam e morrem por elas, mesmo quando essas representações não exprimem, de forma direta, nem as suas necessidades, nem as suas aspirações, nem a sua classe.

Gorender (1989, p.19) também afirma em seus estudos que manipulação e propagandismo têm sua matriz na ideologia como 'traduções' a níveis culturais inferiores e para enfrentamento de injunções imediatistas. Exemplo disso pôde ser observado em janeiro de 1999 quando dos ataques sofridos pelo real. A imprensa televisiva apelou para os 'especialistas' em economia que se empenharam em mostrar ao povo que a culpa da crise não estava no governo, sempre tão inteligente e bem intencionado, mas na globalização[6], 'essa força incontrolável', e no fugidio e instável capital internacional. Deu-se tanta ênfase à premissa segundo a qual a ajuda do FMl era a salvação do país que a população brasileira passou a torcer para que os homens do Fundo fossem camaradas e emprestassem mais dinheiro ao Brasil.

\section{Considerações finais}

Há uma declinação política da significação que resulta no silenciamento como forma não de calar mas de dizer 'uma' coisa, para não deixar dizer 'outras' (Orlandi,1997, p.55). 
Retomemos Wittgenstein e Sobriño. Ambos contribuíram sobremaneira com este nosso estudo sobre a linguagem, propondo questionamentos e modelos de análise. Do primeiro, a percepção com que apreendeu o papel do ensino ostensivo das palavras ou da elucidação ostensiva indicou-nos o rumo, ou a estratégia primeira adotada por quem pretende controlar efetivamente os rumos das classes sociais. De Sobriño, a contribuição de que nas entrelinhas do discurso aparentemente neutro há sempre a intencionalidade. Essas certezas devem servir de alerta para os sujeitos, individuais ou coletivos, que estejam em busca da sua cidadania plena. Quando se consegue perceber o engodo, fica mais fácil evitálo.

De qualquer forma, e apesar de os caminhos para a crítica estarem se tornando hoje cada vez mais estreitos, concordamos com Souza Santos (1996, p.109) quando afirma que temos de aprender a ser polifônicos. É evidente que a polifonia é contra as verdades fortes. $E$ ainda bem, pois mais vale uma verdade na mão prudente e democrática que duas a voar no vazio da apodíctica imprudente e autoritária.

Talvez devido ao autoritarismo vigente, ou talvez por não se dar conta de que padece de um violento processo de assujeitamento a formas de pensar pré-concebidas, o fato é que boa parte da população brasileira parece mergulhada no estado de prostração mental mencionado por Batista Jr. E quando uma sociedade se isenta de tomar o seu destino nas mãos, quando de isenta de construir a própria Weltanschauung[7] delegando esse poder a grupos dirigentes mal intencionados, é quase certo que permanecerá constituindo-se como massa de manobra a interesses escusos.

É preciso, então, que os setores esclarecidos e atuantes nas instituições públicas de ensino comecem ou continuem a fazer mais eficazmente a sua parte, que consiste em retirar dos olhos da população a viseira imposta pela ideologia dominante. Como? Adotando a mesma estratégia usada por aqueles setores que têm hoje o controle do povo pela manipulação das suas idéias: a repetição constante e incansável do mesmo discurso. Se optarem pela adoção de um discurso polêmico e, de comum acordo, começarem todos a usar os espaços ainda possíveis nas mídias para dizer sempre as mesmas coisas, ainda que com outras palavras, se usarem o prestígio não de seus cargos nas instituições públicas de ensino (é sempre bom lembrar que funcionário público não é bem visto nestes tempos de catequese neoliberal) mas de seus títulos enquanto especialistas, mestres e doutores, é possível que consigam provocar alterações nessa situação de desarmamento intelectual em que, lamentavelmente, vive boa parte da nação brasileira.

\section{REFERÊNCIAS BIBLIOGRÁFICAS}

ALVES, Rubem. Dogmatismo e tolerância. São Paulo: Edições Paulinas, 1982. BATISTA Jr., Paulo Nogueira. Mitos da 'globalização'. São Paulo: Editora Peres, 1998. COSTA, Marisa V. Trabalho docente e profissionalismo. Porto Alegre: Sulina, 1995. DIAS, Edmundo Fernandes. Leitura e poder. Universidade e sociedade. Ano V, n.09, out., 1995, p.67-70.

GOLDMANN, Lucien. Introdução à sociologia. Cadernos para o diálogo/ nova série. Editora Nova Crítica, s.d. 
GORENDER, Jacob. O nascimento do materialismo histórico. In MARX, K. e ENGELS, F. A ideologia alemã. São Paulo: Martins Fontes, 1989.

MOCHCOVITCH, Luna G. Gramsci e a escola. São Paulo: Ática, 1988.

ORLANDI, Eni P. O lugar das sistematicidades lingüísticas na análise do discurso.

D.E.L.T.A., vol. 10, n.02, 1994: 295-307.

ORLANDI, Eni P. Discurso e leitura. 3.ed., Campinas: Editora da UNICAMP, 1996.

ORLANDI, Eni P. As formas do silêncio: no movimento dos sentidos. Campinas: Editora da UNICAMP, 1997.

ORTIZ, Renato (org.). Pierre Bourdieu. São Paulo: Ática, 1983.

PÊCHEUX, Michel. Semântica e discurso: uma crítica à afirmação do óbvio. Campinas: Editora da UNICAMP, 1995.

PÊCHEUX, Michel. Ler o arquivo hoje. In: ORLANDI, E. (org.). Gestos de leitura. 2.ed., Campinas: Editora da UNICAMP, 1997: 55-66.

SOBRIÑO, Encarnación. Ideologia e educação: reflexões teóricas e propostas metodológicas. São Paulo: Cortez: Autores Associados, 1986.

SOUZA SANTOS, Boaventura de. Pela mão de Alice. São Paulo: Cortez, 1996.

WITTGENSTEIN, Ludwig. Investigações filosóficas. In: Os pensadores Wittgenstein e Moore. São Paulo: Nova Cultural, 1989: 8-222.

Notas:

[1] As formações discursivas são componentes das formações ideológicas e determinam o que pode e deve ser dito a partir de uma posição em uma conjuntura dada (Orlandi, 1996, p.18).

[2] A esse processo podemos chamar de 'massificação includente' que ocorre quando se dá a incorporação do discurso ou, pelo menos, a concordância formal com ele, traduzida pela passividade, ou então de "massificação excludente' que, embora mais rara, ocorre quando parte da população se insurge publicamente contra determinadas arbitrariedades das autoridades constituídas. Exemplo dessa última é o surgimento de movimentos populares como o Movimento Sem Terra.

[3] Por leitura deve-se compreender, aqui, o trabalho de interpretação da realidade social, política, econômica, etc.

[4] Orlandi (1997, p.43) aponta essa imposição do silenciamento como uma característica do universo das ciências ao dizer que, nesse universo, é bem conhecido o fato de que há teorias que não deixamos significar.

[5] Não estamos querendo, aqui, criticar a atuação dos intelectuais ligados ideologicamente ao povo. Consideramos tão somente que os intelectuais alinhados ao pensamento gramsciano não dispõem do controle dos meios de comunicação, que se constituem inegavelmente, hoje, como a forma mais rápida e eficiente de catequizar as massas.

[6] Qualquer observador atento se dá conta que, no dizer dos manipuladores da opinião pública, a globalização se transforma, de acordo com a conveniência, ora em bruxa, ora em fada, mesmo que sempre mostrada como um 'processo irreversível' do qual uma 'nação moderna' não pode se excluir. 
[7] Visão de mundo que constrói a partir da reflexão e do estudo, onde não cabe a ingenuidade. 